\title{
Willem Bilderdijk: paixão italiana, amor holandês
}

\author{
Sien Van Den Hoof
}

\section{O poeta}

O poeta holandês Willem Bilderdijk nasceu em 1756, em Amsterdã. Por causa de um acidente sofrido aos seis anos de idade, Bilderdijk é obrigado a ficar em casa a maior parte do tempo, por cerca de dez anos. Por conseguinte, dedica-se a uma vida de estudos intensivos, consumindo todos os livros que estavam ao seu alcance. Torna-se um autodidata em várias disciplinas.

Em 1776, com vinte anos de idade, Bilderdijk recebe de gouden penning, "a medalha de ouro", da sociedade de poetas Kunst Wordt door Arbeid Verkreegen [A Arte é Realizada através do Trabalho], pelo seu poema "Invloed van de dichtkunst op het staetsbestuur" [Influência da arte poética no governo do Estado]. A partir desse momento, o talento poético do jovem Bilderdijk passa a ser reconhecido formalmente e ele será premiado por várias outras instituições. Três anos mais tarde, Bilderdijk publica uma coleção de poemas eróticos, Mijn verlustiging, "O meu regozijo". O amor será um tema constante na sua obra poética posterior.

Embora tenha praticado vários gêneros literários e realizado um trabalho importante como tradutor, principalmente de clássicos 
latinos e gregos. Bilderdijk é conhecido, sobretudo, pela sua vasta obra poética. Ela deu margem a várias controvérsias, tanto na época da sua primeira publicação, por causa dos seus temas às vezes ousados, quanto nos séculos posteriores, nos meios acadêmicos, por causa da ambiguidade do artista. De fato, de um ponto de vista formal, a produção poética de Bilderdijk pode ser caracterizada como classicista, mas quanto à sua teorização estética, o poeta defende algumas noções do romantismo.

A vida de Willem Bilderdijk é uma vida de transtornos e mudanças. O poeta formou-se em direito na Universidade de Leiden e mudou-se para a Haia, onde atuou como advogado. Em 1785, casase com Catharina Rebecca Woesthoven. Em 1795, depois da invasão da Holanda pelo Exército francês, Bilderdijk recusa-se a prestar juramento para o novo regime, uma decisão que leva ao seu exílio na Inglaterra. Em Londres, apaixona-se pela jovem Katharina Wilhelmina Schweickhardt. O pai de Katharina, o pintor Hendrik Willem Schweickhardt, não aceita o relacionamento e o casal vive um período de amor a distância. Depois, Willem e Katharina fogem para Alemanha, e Bilderdijk separa-se oficialmente da primeira esposa.

Em 1806 Bilderdijk volta para a cidade de Leiden, na Holanda, onde, entre outras atividades, dá aulas de holandês a Luís Napoleão e continua sua produção poética e teatral. A partida de Luís Napoleão faz com que a família Bilderdijk se encontre novamente na pobreza e eles mudam de cidade várias vezes.

Apesar das condições de vida difíceis, Bilderdijk sempre continuou produzindo poesia e, nos últimos anos da sua vida, atuou como professor particular de história holandesa para um pequeno círculo de jovens intelectuais.

Bilderdijk faleceu em 1831 em Haarlem. 


\section{O poema}

\section{Het Italiaansch}

U minne ik teer, o taal van lust en weelde, Die 't stug Latijn in dartele ontucht teelde; Die als de kus op malsche lippen smelt, En 't hart doorstroomt met Liefdes algeweld. Uw woorden zijn uit zacht satijn geweven, In toontjes die op donzen vlerkjes zweven; Uw letters, zoet als Zefirs ademzucht; En heel uw spraak, één Lieve Lentelucht. Maar meer nog u, o Vaderlandsche tonen, Waar kracht en ziel en hemelgeest in wonen; Die met den zang van Po en Tyber vliet, En Godenlust door hart en aders giet, Maar rijzen kunt, en onder 't boezemstreelen, Met Godenwil op 't menschlijk hart bevelen, Zijn stormen stilt, zijn ijs in vlammen zet, En donders voert, en bliksemend verplet.

(citado em De Jong 1973:15)

Embora Willem Bilderdijk tenha iniciado a sua carreira literária com uma coleção de poemas eróticos explícitos, escolhemos, para este trabalho, um poema implicitamente erótico. Trata-se do poema "Het Italiaansch" ["A língua italiana"], que foi publicado pela primeira vez na coleção Krekelzangen ["Cantos de cigarra"], em 1822. Para escrever "Het Italiaansch", Bilderdijk inspirou-se nesta homenagem de Byron à língua italiana: 
Sien Van Den Hoof. Willem Bilderdijk: paixão italiana, amor holandês

I love the language, that soft bastard Latin,

Which melts like kisses from a female mouth,

And sounds as if it should be writ on satin,

With syllables which breathe of the sweet South,

And gentle liquids gliding all so pat in,

That not a single accent seems uncouth,

Like our harsh northern whistling, grunting guttural,

Which we're obliged to hiss, and spit, and sputter all.

(citado em De Jong 1973:16)

A paixão de Lord Byron pelas culturas mediterrâneas é bem conhecida e exteriorizou-se não só na sua produção literária, mas também na sua atuação política na Grécia.

A relação de Bilderdijk com a língua italiana tem um caráter mais íntimo. O italiano era uma das várias línguas que Bilderdijk dominava. Todavia, a língua em questão tornou-se mais significativa quando Bilderdijk se apaixonou pela sua aluna Katharina em Londres, a quem dava aulas de italiano e de francês. Começou a escrever-lhe poemas em italiano que, porém, segundo o estudo de Martien J.G. de Jong sobre a relação entre Bilderdijk e a língua italiana (1973), eram de pouca qualidade e podem ser considerados como meros exercícios imitativos dos sonetos de Petrarca (1973:12). $\mathrm{Na}$ fase seguinte da história de amor entre Willem e Katharina, quando o casal teve de separar-se, uma parte da correspondência realizou-se em italiano. Por conseguinte, a língua italiana, que em geral é muitas vezes considerada como uma língua sensual pelos falantes de línguas germânicas, sugeria, para Bilderdijk, conotações amorosas bem mais específicas.

Porém, Bilderdijk não se limita a um elogio a essa língua da (sua) paixão. De fato, a segunda metade do poema é uma homenagem à língua materna do poeta, o holandês. Esta língua é apresentada como uma língua forte, poderosa, mas que também tem uma 
determinada sensualidade, talvez menos evidente e mais sutil do que a da língua italiana.

Como já mencionamos acima, o poema talvez não seja explicitamente erótico, mas Bilderdijk consegue exprimir o caráter sensual das duas línguas e o efeito passional que podem exercer nos seus amantes. O poeta consegue transmitir essa idéia mediante o uso, em primeiro lugar, de palavras que se referem diretamente ao amor e à paixão, tanto nas suas formas ingênuas como nas suas manifestações menos inocentes: minnen, "amar"; lust, "paixão"; ontucht, "vício"; kus, "beijo"; liefdes, "amores"; hart, "coração". Ele também escolhe termos que podemos situar no campo semântico dos sentidos, instrumentos imprescindíveis na experiência erótica: malse lippen, "lábios macios"; zacht satijn, "cetim suave"; zoete letters, "letras doces"; lentelucht, "ar primaveril"; strelen, "acariciar". Finalmente, Bilderdijk também lança mão da antítese, figura de estilo comum na poesia amorosa clássica, utilizada para exprimir os efeitos ambíguos provocados pela paixão, sentimentos tanto de prazer, quanto de sofrimento: godenlust e godenwil, "paixão" e "vontade" divinas; kracht en ziel,"força e alma"; ijs in vlammen zetten, "acender o gelo".

\section{A tradução}

\section{A Língua Italiana}

Amo-te ternamente, língua lassa,

Que plantou o latim em terra devassa;

Que como o beijo em lábios ternos se desfaz,

E inunda de paixão o coração em paz.

As palavras tecidas de cetim suave,

Os seus tons, asas macias duma ave;

Letras doces como o Zéfiro que suspira;

Toda a fala, a primavera que respira. 
Sien Van Den Hoof. Willem Bilderdijk: paixão italiana, amor holandês

Mas mais em vós, tons da terra dos nossos pais,

Moram força, alma, espírito celestiais;

E como o canto do Pó e do Tibre correis,

Os prazeres divinos pelas veias verteis,

Mas surgis, e acariciando o seio,

Gerais no peito dos homens um anseio,

As tormentas acalmais, o gelo queimais,

Trazeis os trovões, e fulgurantemente esmagais.

Na tradução desse poema de Bilderdijk, tentamos recuperar tanto os aspectos formais do poema em holandês (como a rima e a estrutura silábica dos versos) quanto o nível da semântica, já que os dois planos - formal e semântico - colaboram no processo de produção do efeito provocado pelo poema no leitor.

De um ponto de vista formal, o poema em holandês contém dezoito versos. O primeiro verso tem doze sílabas, e a partir do segundo e do terceiro versos há uma alternância regular entre versos de dez e de onze sílabas. Tentamos recuperar esse primeiro aspecto formal na tradução, introduzindo uma estrutura igualmente simétrica, mas de maneira invertida: a partir do primeiro e do segundo versos, há uma alternância entre versos de doze e de treze sílabas, mas o último verso contém quinze sílabas.

Quanto à rima, importa fazer uma distinção entre a rima externa, no final dos versos, e as aliterações, dentro dos versos. No poema original, observam-se rimas ricas externas. Embora os sons [e], [e:] e [å] tenham uma presença importante nas rimas, todas aparecem só uma única vez. Na nossa tradução, nenhuma rima aparece mais que uma vez. A presença importante do /a/, sob as formas fonéticas [a], [á] e [aj], pode considerar-se como um equivalente das várias manifestações do /e/ no poema original.

Observa-se várias aliterações no poema original. Algumas delas são, por exemplo: teer, taal "ternamente, língua"; zoet als zefirs 
"doces como (...) de Zéfiro"; lieve lentelucht "ar primaveril amável"; stormen stilt "acalma tormentas". Na tradução tentamos recuperar esta presença de aliterações de maneira geral, sem nos focalizar nos versos específicos nos quais se encontram no poema em holandês. Assim, algumas das aliterações da tradução são: "língua luxosa", "asas macias duma ave", "tons da terra", "trazeis os trovões".

No que diz respeito à língua em geral, importa observar em primeiro lugar que a língua do poema original não é o holandês falado hoje em dia, mas o holandês do século 19. Isso se manifesta, porém, sobretudo nas regras ortográficas, e menos no vocabulário. Concordamos com o teórico da tradução Catford quando este afirma em A Linguistic Theory of Translation (1965) que, no caso da tradução de um texto-fonte que se situa num outro état de langue, "equivalence of absolute location in time is normally neither possible nor desirable." (1965:89) Todavia, o aspecto arcaico recupera-se, talvez, de maneira limitada, através do uso do pronome "vós".

Quanto à semântica, a tradução afasta-se muito pouco do sentido literal do poema original. Em alguns versos, porém, foi necessário excluir uma palavra, ou optar por uma tradução menos literal, por causa da estrutura silábica ou da rima. Assim, na segunda linha, perdeu-se a palavra stug, "ríspido" do original. Na sexta linha, o verbo zweven, "pairar" foi substituído na tradução pelo substantivo "ave". A tradução da décima quarta linha Met Godenwil op 't menschlijk hart bevelen afasta-se bastante de uma tradução literal, que seria algo como "Com vontade divina [podeis] mandar no coração humano". Todavia, a tradução também exprime o grande poder que a língua exerce no coração, sem incluir a comparação com a força divina.

\section{Conclusão}

Escolhemos esse poema de Willem Bilderdijk pelo alto grau de identificação que experimentamos com o que exprime. Com efeito, em primeiro lugar, como amante de línguas, reconhecemos a 
Sien Van Den Hoof. Willem Bilderdijk: paixão italiana, amor holandês

paixão que provoca dentro de nós uma língua românica, exótica, sensual, que em nosso caso seria o português. Por outro lado, também nos identificamos com o amor fiel e a admiração que sentimos pela nossa língua materna, o holandês, intensificados, talvez também no caso de Bilderdijk, pela vivência no exterior.

Todavia, além desse efeito de identificação pessoal, consideramos que esse poema também reflete a situação do tradutor, que se encontra entre dois (ou mais) amores: por um lado, a obsessão por uma língua estrangeira, que muitas vezes permanece, pelo menos parcialmente, desconhecida, misteriosa e, por isso, extremamente atraente; por outro lado, o tradutor sempre volta à sua língua materna para redescobrir a sua força, a sua riqueza e a sua beleza. E ela, a língua-mãe, o protege, sempre espera por ele, pacientemente, para acolhê-lo de braços abertos.

\section{Referências:}

CATFORD, J. C. A linguistic theory of translation. London: Oxford University Press, 1965, 103p.

DE JONG, Martien J. G. Taal van lust en weelde: Willem Bilderdijk et la littérature italienne. Namur: Presses Universitaires de Namur, 1973. $145 \mathrm{p}$.

Museu Bilderdijk, http://www.bilderdijkmuseum.vu.nl/, acesso em 24 de junho 2008.

Página da Biblioteca Digital de Letras Holandesas dedicada a Willem Bilderdijk, http://www.dbnl.be/auteurs/auteur.php?id=bild002, acesso em 24 de junho 2008.

Página da Biblioteca Nacional Holandesa dedicada a Willem Bilderdijk, http://www.kb.nl/dichters/bilderdijk/bilderdijk-01.html, acesso em 24 de junho 2008. 